Proceedings

\title{
Formation of Carbon Nanofibers under Moderate Synthesis of Carbon Gels ${ }^{\dagger}$
}

\author{
Samantha L. Flores-López, Sara F. Villanueva, Miguel A. Montes-Morán and Ana Arenillas* \\ Instituto de Ciencia y Tecnología del Carbono, INCAR-CSIC, Francisco Pintado Fe, 26, 33011 Oviedo, Spain; \\ samantha.f@incar.csic.es (S.L.F.-L.); s.villanueva@incar.csic.es (S.F.V.); miguel.montes@csic.es (M.A.M.-M.) \\ * Correspondence: ana.arenillas@csic.es \\ + Presented at the 2nd International Online-Conference on Nanomaterials, 15-30 November 2020; Available \\ online: https://iocn2020.sciforum.net/.
}

Published: 15 November 2020

\begin{abstract}
Carbon nanomaterials with different structures (i.e., fibers, tubes, spheres) have been widely studied in the last decades for many applications in the fields of energy, electronics, catalysis and bio-nanotechnology with promising results. The synthesis of these materials includes methodologies such as catalysis, vapor- or electro-deposition and the use of templates; however, it is still necessary to develop effective processes for their mass production. On the other hand, carbon gels are considered very interesting materials for a wide range of applications due to their textural and chemical properties. But certainly, the most valued property of this kind of materials is the ease when tuning their morphology and porous properties. The sol-gel chemistry is controlled by parameters including the type and amount of reactants, solvents, catalyst and temperature; that influence the nucleation, growth and interconnectivity of the resultant network. From a precursor mixture of resorcinol-formaldehyde, and the selection of moderate synthesis conditions (i.e., atmospheric pressure and temperatures under $90^{\circ} \mathrm{C}$ ), this work shows how the heating process during the synthesis alters the morphology of the carbon gel, changing from the typical polymeric nodules to the formation of nanofibers.
\end{abstract}

Keywords: nanofibers; RF carbon gels; synthesis conditions; sol-gel process

Publisher's Note: MDPI stays neutral with regard to jurisdictional claims in published maps and institutional affiliations.

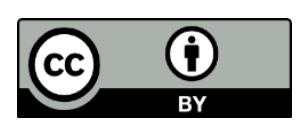

(C) 2020 by the authors. Submitted for possible open access publication under the terms and conditions of the Creative Commons Attribution (CC BY) license (http://creativecommons.org/licenses/by/4.0/). 